\title{
A Method for the Calculation of the AC-Side Admittance of a Modular Multilevel Converter
}

\author{
Luca Bessegato, Student Member, IEEE, Lennart Harnefors, Fellow, IEEE, Kalle Ilves, Member, IEEE, \\ Staffan Norrga, Member, IEEE,
}

\begin{abstract}
Connecting a modular multilevel converter to an ac grid may cause stability issues, which can be assessed by analyzing the converter ac-side admittance in relation to the grid impedance. This paper presents a method for calculating the ac-side admittance of modular multilevel converters, analyzing the main frequency components of the converter variables individually. Starting from a time-averaged model of the converter, the proposed method performs a linearization in the frequency domain, which overcomes the inherent nonlinearities of the converter internal dynamics and the phase-locked loop used in the control. The ac-side admittance obtained analytically is firstly validated by simulations against a nonlinear time-averaged model of the modular multilevel converter. The tradeoff posed by complexity of the method and the accuracy of the result is discussed and the magnitude of the individual frequency components is shown. Finally, experiments on a down-scaled prototype are performed to validate this study and the simplification on which it is based.
\end{abstract}

Index Terms-Modular multilevel converters, admittance, linearization techniques, frequency-domain analysis, stability.

\section{INTRODUCTION}

$\mathbf{M}$ ODULAR multilevel converters (MMCs) [1], [2] are a class of topologies that is currently preferred in many high-power applications, such as voltage source converter (VSC) based HVDC systems, static synchronous compensators (STATCOMs), medium-voltage motor drives, and static traction converters [3]-[6]. The main advantages that make MMCs suitable for high-power applications are modularity, scalability, low power losses, and low harmonic distortion.

In recent years, MMCs have been intensively studied, with focus mainly on dynamic performance [7], [8], modulation techniques [9]-[11], modeling and control [4], [5], steady-state analysis [12]-[14], operation under unbalanced grid conditions [15], and submodule implementations [16]. However, a topic where research is still limited is system stability. Similarly to two-level VSCs, stability problems may arise when connecting an MMC to an ac grid, leading to amplification or destabilization of resonances and other stability issues. The stability of the system formed by the ac grid and the power converter can be studied using frequency-domain methods, such as the impedance-based stability criterion [17], the passivitybased stability assessment [18], or the net-damping criterion [19]. For instance, when using the impedance-based stability

Manuscript received February 16, 2018; revised June 20, 2018; accepted July 30, 2018.

L. Bessegato and S. Norrga are with the Royal Institute of Technology (KTH), Stockholm 100 44, Sweden (e-mail: lucabe@kth.se; norrga@kth.se).

L. Harnefors and K. Ilves are with ABB Corporate Research, Västerås 721 78, Sweden (e-mail: lennart.harnefors@se.abb.com; kalle.ilves@se.abb.com).
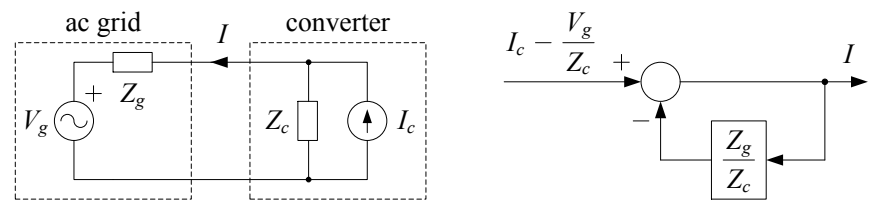

Fig. 1. Small-signal representation of the system formed by the ac grid and the power converter (left) and its expression as a negative feedback system (right).

criterion, the ac grid is modeled by its Thevenin equivalent circuit, $V_{g}$ and $Z_{g}$, while the converter is modeled by its Norton equivalent circuit, $I_{c}$ and $Z_{c}$, as shown in Fig. 1. Using this linear representation, valid only for small-signal analysis, the current $I$ flowing from the converter to the grid can be expressed as

$$
I(s)=\left[I_{c}(s)-\frac{V_{g}(s)}{Z_{c}(s)}\right] \frac{1}{1+Z_{g}(s) / Z_{c}(s)} .
$$

Assuming that $I_{c}, V_{g}$, and $1 / Z_{c}$ are stable, the stability of the interconnected system depends on the stability of the second term on the right-hand side of (1), which can be expressed as a negative feedback system, shown in Fig. 1. By linear control theory, this feedback system is stable if and only if $Z_{g}(s) / Z_{c}(s)$ satisfies the Nyquist stability criterion. Thus, the expression of the converter a-side impedance, or admittance, can be used for stability analysis.

The converter ac-side admittance has been extensively documented for the two-level VSC topology [20], [21]. Still, these results cannot be directly extended to MMCs, mainly due to their internal-dynamic behavior being inherently more complex than the two-level VSCs. Reference [22] presents a model of the MMC impedance; however, the submodule capacitor-voltages are treated as constant, effectively modeling the MMC as a two-level VSC. Later in [23], the same authors improve the study by including the capacitor-voltage dynamics and propose a new impedance model based on harmonic state-space modeling, a method that involves extensive matrix manipulation. Still, the impact of the phase-locked loop (PLL), needed for synchronization with the ac grid, is not investigated. Additionally, in [24], the same authors propose an MMC impedance model based on harmonic linearization, deriving the solution analytically by elimination of variables. The proposed derivation is mathematically intricate; therefore, it cannot be easily adjusted to include additional frequency components, different control strategies, or the PLL dynamics. The authors of [25] and [26] derive an analytical model 
of the MMC ac-side admittance by developing a smallsignal model of the MMC, including its internal dynamics and considering different ac-side control strategies. Compared to small-signal modeling, methods that analyze the single frequency components of the MMC variables are an interesting alternative, as they not only allow to obtain the expression of the ac-side admittance, but also describe how the MMC internal variables are impacted by a perturbation in the ac-grid voltage. Reference [27] develops a sequence impedance model for MMCs, using multiharmonic linearization. The derivation is accurate and thorough; yet, it involves extensive matrix manipulation and it requires obtaining the steady-state solution by solving nonlinear equation, or by simulation.

This paper aims to, at least partially, bridge the mentioned gaps in the state of the art. Specifically, a combination of harmonic linearization and frequency-domain representation is used to overcome the system nonlinearities, building a linear system which describes the main frequency components of the MMC internal variables individually. This method provides insight on how the spectra of the MMC internal variables are impacted by a perturbation term in the ac-grid voltage and how the converter parameters shape the ac-side admittance. This study is aimed at achieving good accuracy while avoiding laborious mathematical manipulation, in order to keep the complexity to a minimum level. The MMC internal dynamics and the PLL, which are sources of nonlinearities, are included in the proposed admittance model. However, in order to contain the volume of this study, the MMC is operated with a fixed sinusoidal modulation pattern; further investigation, e.g., evaluating the impact of different ac-side control strategies on the admittance, will be covered in future studies. The proposed method is verified experimentally on a down-scaled MMC prototype, in order to assess the validity of this study, and the simplifications on which it is based, in relation to a real MMC.

An early version of this study is presented in [28]. Compared with the previously published results, the main additions and improvements presented in this paper are: 1) a revised analytical derivation of the ac-side admittance, based on Fourier coefficients instead of phasors, which is more suitable when using linearization in the frequency domain; 2) a frequency-domain model of the PLL, which allows for quantifying the impact of the PLL dynamics on the acside admittance; 3) the MMC operated with fixed sinusoidal modulation pattern, which exposes how the MMC internal dynamics shape the admittance in absence of feedback control, providing foundation for future work; 4) an analysis of the main perturbation frequency components resulting from the system nonlinearities and their impact on the accuracy of the results; 5) the experimental verification of the proposed method.

The paper is organized as follows. Section II describes the models used in this study: the MMC model, based on time averaging, and the PLL model. Section III presents the proposed method for ac-side admittance calculation, based on linearization in the frequency domain. Section IV shows the results used to validate the study, obtained from simulations and experiments. Finally, Section V summarizes this work and

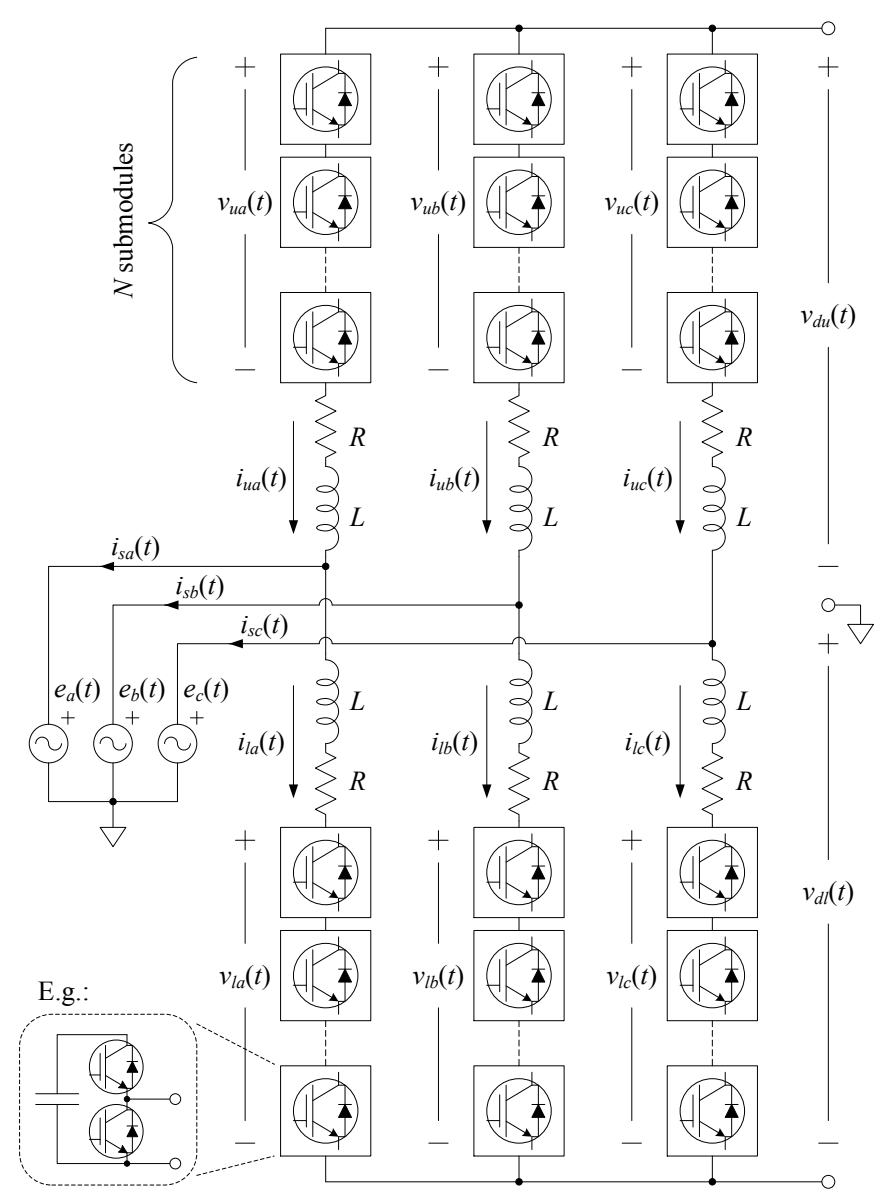

Fig. 2. Modular multilevel converter topology; a half-bridge submodule is shown as example of submodule implementation.

its conclusions.

\section{SYSTEM MODEL}

The MMC topology, depicted in Fig. 2, consists of three upper arms and three lower arms, each comprised of $N$ submodules, typically half-bridge or full-bridge submodules. Each submodule includes switching elements, which allow the insertion or bypassing of an energy-storage element, typically a capacitor. An arm inductor, with inductance $L$, is used for limiting the switching harmonics in the arm current. In addition, a parasitic resistance $R$ is included to account for the losses in the arm. Stray inductances in the converter arms can be neglected, as they appear in series with the arm inductor, which is considerably larger.

In this paper, a time-averaged model of the MMC is used, i.e., the switching operations are neglected [29]; furthermore, it is assumed that the submodule capacitances are balanced within the arm, meaning that the individual submodulecapacitance dynamics are also neglected. The converter is modeled on a per-phase basis, dropping the subscript denoting the phase when not needed.

In this study, the converter is operated in rectifier mode, with a resistive load on the dc side. Although having a resistive load is uncommon for MMCs, it allows for validating the study 
using an experimental setup, which is configured likewise, as shown in Section IV-B. This choice of configuration does not jeopardize the validity of this study, which can easily be reverted to the common case of a stiff dc-bus voltage.

The point-of-common-coupling (PCC) voltage,

$$
e(t)=e_{1} \cos [\vartheta(t)], \quad \text { with } \quad \vartheta(t)=\omega_{1} t=2 \pi f_{1} t,
$$

is a pure cosine wave with no phase shift, because $\vartheta(t)$ is chosen as reference angle.

\section{A. Dynamics of the Converter}

The arm-current dynamics are described using Kirchhoff's voltage laws,

$$
\begin{gathered}
L \frac{d i_{u}(t)}{d t}+R i_{u}(t)=v_{d u}(t)-v_{u}(t)-e(t) \\
L \frac{d i_{l}(t)}{d t}+R i_{l}(t)=v_{d l}(t)-v_{l}(t)+e(t),
\end{gathered}
$$

where $i_{u}(t)$ is the upper-arm current, $i_{l}(t)$ is the lower-arm current, $v_{u}(t)$ is the upper-arm voltage, $v_{l}(t)$ is the lower-arm voltage, $v_{d u}(t)$ is the upper-dc-side voltage, $v_{d l}(t)$ is the lowerdc-side voltage. As the converter is connected to a resistive load on the dc side, the dc-side voltages are functions of the arm currents, i.e.,

$$
\begin{aligned}
& v_{d u}(t)=-\frac{R_{d}}{2}\left[i_{u a}(t)+i_{u b}(t)+i_{u c}(t)\right] \\
& v_{d l}(t)=-\frac{R_{d}}{2}\left[i_{l a}(t)+i_{l b}(t)+i_{l c}(t)\right],
\end{aligned}
$$

where $R_{d}$ is the resistance of the load.

Modeling the converter using its time-averaged model allows to express the arm voltages as

$$
v_{u, l}(t)=n_{u, l}(t) v_{C u, l}^{\Sigma}(t),
$$

where $n_{u, l}(t)$ are the insertion indices and $v_{C u, l}^{\Sigma}(t)$ are the sum-capacitor-voltages, defined as

$$
v_{C u, l}^{\Sigma}(t)=\frac{1}{C} \int n_{u, l}(t) i_{u, l}(t) d t+v_{C 0}^{\Sigma},
$$

where $v_{C 0}^{\Sigma}$ is the average sum-capacitor-voltage and $C$ is the arm capacitance, defined as the submodule capacitance divided by $N$. The converter is operated with fixed sinusoidal modulation pattern, i.e.,

$$
\begin{aligned}
& n_{u}(t)=\frac{1}{2}-\frac{m_{1}}{2} \cos \left(\hat{\omega}_{1} t\right) \\
& n_{l}(t)=\frac{1}{2}+\frac{m_{1}}{2} \cos \left(\hat{\omega}_{1} t\right),
\end{aligned}
$$

where $m_{1}$ is the modulation index and the estimated PCC voltage angle $\hat{\omega}_{1} t$ is provided by the PLL, as shown in Fig. 3 .

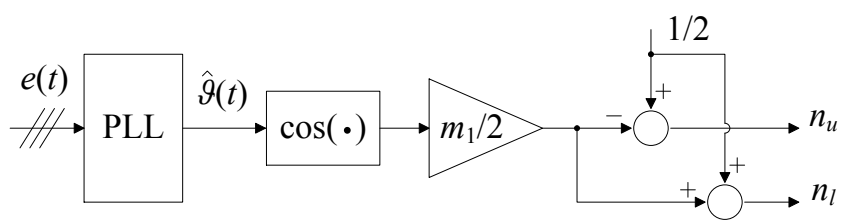

Fig. 3. Block diagram of the MMC control scheme.



Fig. 4. PLL block diagram.

\section{B. Phase-Locked Loop}

The purpose of the PLL is to provide the MMC with the estimation $\hat{\vartheta}(t)$ of the PCC voltage angle $\vartheta(t)$, which is used in (9) and (10), i.e.,

$$
\vartheta(t)=\omega_{1} t \stackrel{\mathrm{PLL}}{\longrightarrow} \hat{\vartheta}(t)=\hat{\omega}_{1} t .
$$

The PLL employs a $a b c / d q$ transformation, using the $q$-signal to drive a feedback loop built around the transformation itself, as shown in Fig. 4. The input of the transformation is, for phase $a$,

$$
a(t)=e(t) / e_{1}=\cos [\vartheta(t)],
$$

resulting in the $q$-signal

$$
\cos [\vartheta(t)] \stackrel{\text { abc/dq }}{\longrightarrow} \sin [\vartheta(t)-\hat{\vartheta}(t)] .
$$

As shown in Fig. 4, the feedback loop includes a low-pass filter

$$
H_{f}(s)=\frac{\omega_{f}^{2}}{s^{2}+\sqrt{2} \omega_{f} s+\omega_{f}^{2}},
$$

a proportional gain $\alpha_{p}$, a feedforward of the nominal angular frequency $\omega_{1}$, and an integrator.

The PLL is a nonlinear system due to the $a b c / d q$ transformation. However, since $\hat{\vartheta}(t)$ tracks $\vartheta(t)$, the $q$-axis signal can be linearized as

$$
\sin [\vartheta(t)-\hat{\vartheta}(t)] \simeq \vartheta(t)-\hat{\vartheta}(t) .
$$

This allows to model the PLL as a linear feedback system, as shown in Fig. 5.

A second source of nonlinearities is the cosine operator in (9) and (10). Expressing $\hat{\vartheta}(t)$ as

$$
\hat{\vartheta}(t)=\omega_{1} t+\varepsilon(t),
$$

where $\omega_{1} t$ is the integral of the feedforward term and $\varepsilon(t)$ is the integral of the output of the proportional gain, allows to express the estimated signal $\hat{a}(t)$ as

$$
\begin{aligned}
\hat{a}(t) & =\cos \left[\omega_{1} t+\varepsilon(t)\right] \\
& =\cos \left(\omega_{1} t\right) \cos [\varepsilon(t)]-\sin \left(\omega_{1} t\right) \sin [\varepsilon(t)] .
\end{aligned}
$$




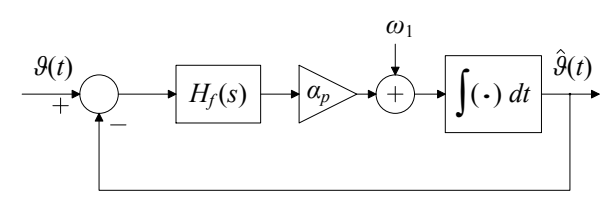

Fig. 5. PLL model with linearized $a b c / d q$ transformation.

Since $\hat{\vartheta}(t)$ tracks $\vartheta(t)$, the previous equation is linearized for $\varepsilon(t) \simeq 0$, resulting in

$$
\hat{a}(t) \simeq \cos \left(\omega_{1} t\right)-\sin \left(\omega_{1} t\right) \varepsilon(t) .
$$

The linearized equations (15) and (18) will prove useful in Section III-B, when deriving the frequency response of the PLL.

\section{AC-Side Admittance Calculation}

The ac-side admittance of the MMC is defined as the ratio between the frequency-domain representation of current and voltage at the MMC ac terminals, with the current flowing towards the MMC, i.e.,

$$
Y_{a c}(f)=-\frac{I_{s}(f)}{E(f)}
$$

In other words, $Y_{a c}(f)$ measures the current response of the MMC when a voltage is applied to its ac terminals.

Because of the nonlinear behavior of the MMC, caused by the multiplications in (7) and (8), $Y_{a c}(f)$ cannot be calculated using linear methods. Classic linearization methods, either in stationary coordinates or in synchronous coordinates, cannot be applied either, because there are several frequency components that needs to be considered when calculating $Y_{a c}(f)$. Instead, harmonic linearization [30] [31] is used for tackling the problem.

Harmonic linearization is a technique that develops a smallsignal linear model for a nonlinear system along a periodically time-varying operation trajectory. By this method, a harmonic perturbation [i.e., $E\left(f_{p}\right)$ ] is superimposed on the excitation of the system, the resulting response of the variable of interest is determined, and the corresponding component at the perturbation frequency is extracted [i.e., $I_{s}\left(f_{p}\right)$ ].

Because of the nonlinearities of the converter internal dynamics, applying the perturbation term $E\left(f_{p}\right)$ affects the frequency spectra of the converter variables; this generates frequency components at $f_{p}$, multiples of $f_{p}$, and combinations of these with the steady-state frequency components through addition and subtraction. Under the assumption that the applied perturbation is small, i.e.,

$$
E\left(f_{p}\right) \ll E\left(f_{1}\right),
$$

harmonic linearization assures that the multiples of $f_{p}$ can be neglected without compromising the accuracy of the result.

Before proceeding with the calculation of the ac-side admittance, a brief review of time- and frequency-domain representation, highlighting their usefulness in this study, is presented.

\section{A. Time- and Frequency-Domain Representation}

The signals analyzed in this study are real-valued periodic functions, represented in the time domain as, e.g.,

$$
\begin{aligned}
x(t) & =x_{0}+x_{1} \cos \left(2 \pi f_{1} t+\varphi_{1}\right) \\
& =x_{0}+\frac{1}{2} x_{1}\left[e^{j\left(2 \pi f_{1} t+\varphi_{1}\right)}+e^{-j\left(2 \pi f_{1} t+\varphi_{1}\right)}\right] .
\end{aligned}
$$

These signals can be compactly represented by using complex coefficients, which encapsulate the amplitude and the phase at specific frequencies, i.e.,

$$
x(t)=X(0)+X\left(f_{1}\right) e^{j 2 \pi f_{1} t}+X\left(-f_{1}\right) e^{-j 2 \pi f_{1} t},
$$

where

$$
X(f)= \begin{cases}\frac{1}{2} x_{1} e^{j \varphi_{1}} & \text { for } f=f_{1} \\ x_{0} & \text { for } f=0 \\ \frac{1}{2} x_{1} e^{-j \varphi_{1}} & \text { for } f=-f_{1}\end{cases}
$$

These coefficients effectively describe the frequency components of $x(t)$ and, in addition, they coincide with the Fourier coefficients of $x(t)$.

Since $x(t)$ is a real-valued function, $X(f)$ features Hermitian symmetry about $f=0$, i.e.,

$$
X(-f)=X(f)^{*},
$$

where $X(f)^{*}$ is the complex conjugate of $X(f)$. This property ensures that the negative frequency components of $x(t)$ can always be obtained from their positive counterparts, meaning that it is sufficient to analyze the positive spectra of the variables of interest.

A recurring situation in this study is the multiplication of two real-valued signals, e.g.,

$$
\begin{aligned}
z(t)= & x(t) y(t)=\left[x_{1} \cos \left(2 \pi f_{1} t+\varphi_{1}\right)\right]\left[y_{2} \cos \left(2 \pi f_{2} t+\varphi_{2}\right)\right] \\
= & \frac{1}{2} x_{1} y_{2}\left\{\cos \left[2 \pi\left(f_{1}+f_{2}\right) t+\varphi_{1}+\varphi_{2}\right]\right. \\
& \left.+\cos \left[2 \pi\left(f_{1}-f_{2}\right) t+\varphi_{1}-\varphi_{2}\right]\right\},
\end{aligned}
$$

which is expressed in the frequency domain as

$$
Z(f)= \begin{cases}X\left(f_{1}\right) Y\left(f_{2}\right) & \text { for } f=f_{1}+f_{2} \\ X\left(f_{1}\right) Y\left(f_{2}\right)^{*} & \text { for } f=f_{1}-f_{2} \\ Z\left(f_{1}+f_{2}\right)^{*} & \text { for } f=-\left(f_{1}+f_{2}\right) \\ Z\left(f_{1}-f_{2}\right)^{*} & \text { for } f=-\left(f_{1}-f_{2}\right)\end{cases}
$$

where $X\left(f_{1}\right)=\frac{1}{2} x_{1} e^{j \varphi_{1}}$ and $Y\left(f_{2}\right)=\frac{1}{2} y_{2} e^{j \varphi_{2}}$. Notice that when calculating $Z(f)$, if $X\left(f_{1}\right)$ is known, then $Z(f)$ becomes a linear function of $Y\left(f_{2}\right)$.

Situations similar to (26) are often encountered when calculating the perturbation terms in Section III-B. Perturbation frequency components resulting from a multiplication are always the product of a steady-state and a perturbation value. Therefore, knowing the steady-state solution allows the perturbation solution to be obtained using linear methods. 
TABLE I

ANALYZED FREQUENCY COMPONENTS

\begin{tabular}{c|c|c|c}
\hline \multicolumn{2}{c|}{ Steady-State } & \multicolumn{2}{c}{ Perturbation } \\
\hline Frequency & Sequence & Frequency & Sequence \\
\hline 0 & zero & $f_{p}$ & positive \\
$f_{1}$ & positive & $f_{1}-f_{p}$ & zero \\
$2 f_{1}$ & negative & $f_{1}+f_{p}$ & negative \\
& & $2 f_{1}-f_{p}$ & positive \\
& & $2 f_{1}+f_{p}$ & zero \\
& & $3 f_{1}-f_{p}$ & negative \\
& & $3 f_{1}+f_{p}$ & positive \\
\hline
\end{tabular}

\section{B. Perturbation Solution}

Adding to the PCC voltage (2) the perturbation term

$$
\tilde{e}(t)=e_{p} \cos \left(2 \pi f_{p} t\right) \quad \Longrightarrow \quad E\left(f_{p}\right)=\frac{e_{p}}{2}
$$

generates new frequency components in the converter variables, referred to as perturbation frequency components, due to the nonlinearities of the converter internal dynamics. The choice of frequency components to consider in the analysis impacts the complexity of the study and the accuracy of the result. An intuitive choice is the minimum amount of frequency components necessary to achieve the desired accuracy in the results. The perturbation frequency components considered in this study are listed in Table I; notice that multiples of $f_{p}$ are not considered when using the harmonic linearization method.

In the following, linear expressions describing the perturbation frequency components of the converter variables are derived. Due to the inherent symmetries of the MMC topology, the ac-side admittance can be obtained analyzing only a single arm, e.g., the upper arm of phase $a$. Hence, the attribute "upper-arm" is omitted for simplicity.

For arm current, arm voltage, and sum-capacitor-voltage, the derivations of the different perturbation frequency components are similar. Therefore, only the expressions at $f_{p}$ are presented in this section, while the expressions at the remaining frequencies are given in the Appendix.

Insertion Index: The perturbation frequency components of the insertion index are derived by analyzing the PLL stage-bystage. Firstly, (13) shows that, in the frequency domain, the $a b c / d q$ transformation produces a frequency shift of $-f_{1}$ and a phase shift of $-\pi / 2$, i.e.,

$$
\tilde{A}(f) \stackrel{\mathrm{abc} / \mathrm{dq}}{\longrightarrow} \frac{\tilde{A}\left(f+f_{1}\right)}{j},
$$

where $\tilde{A}(f)$ is the frequency-domain representation of $\tilde{a}(t)=$ $\tilde{e}(t) / e_{1}$. Notice that the frequency shift by $-f_{1}$ adds the term $+f_{1}$ in the argument of $\tilde{A}$ because, e.g., the frequency component at $f=f_{p}$ is shifted to $f=f_{p}-f_{1}$, therefore $\tilde{A}\left(f+f_{1}\right)$ evaluated for $f=f_{p}-f_{1}$ coincides with $\tilde{A}\left(f_{p}\right)$. Then, using the linearized PLL model according to (15), shown in Fig. 5, the closed-loop frequency response of the PLL results

$$
H_{\mathrm{PLL}}(s)=\frac{\alpha_{p} H_{f}(s)}{s+\alpha_{p} H_{f}(s)} .
$$

For the last stage, the linearized expression for the cosine operator (18) is used. That is, the signal $\tilde{\varepsilon}(t)$, which contains the perturbation frequency component, is multiplied by $-\sin \left(\omega_{1} t\right)$. In the frequency domain, this results in

$$
\tilde{\mathrm{E}}(f) \stackrel{\text { cosine }}{\longrightarrow}-\frac{\tilde{\mathrm{E}}\left(f-f_{1}\right)-\tilde{\mathrm{E}}\left(f+f_{1}\right)}{2 j},
$$

i.e., the frequency spectrum $\tilde{\mathrm{E}}(f)$ is scaled by $-1 / 2 j$ and split into two components, one shifted by $f_{1}$ and a second shifted by $-f_{1}$. For clarity, the frequency shifts from (28) and (30) are summarized

$$
f_{p} \stackrel{\text { abc/dq }}{\longrightarrow} f_{p}-f_{1} \stackrel{\text { cosine }}{\longrightarrow}\left\{\begin{array}{l}
f_{p} \\
f_{p}-2 f_{1} .
\end{array}\right.
$$

Equations (27)-(30) are combined together to obtain the first perturbation frequency component, i.e.,

$$
N_{u}\left(f_{p}\right)=-m_{1} \frac{e_{p}}{8 e_{1}} H_{\mathrm{PLL}}\left[j\left(\omega_{p}-\omega_{1}\right)\right],
$$

where $H_{\mathrm{PLL}}(s)$ is evaluated for $s=j\left(\omega_{p}-\omega_{1}\right)$, due to the frequency shift by $-f_{1}$, and (9) adds the factor $-m_{1} / 2$. The second perturbation frequency component of the insertion index is obtained from (30), observing that the two components differ by a factor -1 , i.e.,

$$
N_{u}\left(f_{p}-2 f_{1}\right)=-N_{u}\left(f_{p}\right) .
$$

However, in order to align with the perturbation values selected in Table I, it is chosen to use the negative counterpart of (33) instead, i.e.,

$$
N_{u}\left(2 f_{1}-f_{p}\right)=\left[N_{u}\left(f_{p}-2 f_{1}\right)\right]^{*}=\left[-N_{u}\left(f_{p}\right)\right]^{*} .
$$

Arm Current: Kirchhoffs voltage law (3) expresses the arm current as a linear function of the arm voltage, meaning that each frequency component of $I_{u}(f)$ is only affected by $V_{u}(f)$ at the same frequency. Therefore, expressing (3) in the frequency domain at $f_{p}$ leads to

$$
I_{u}\left(f_{p}\right)+\frac{V_{u}\left(f_{p}\right)}{j \omega_{p} L+R}=-\frac{E\left(f_{p}\right)}{j \omega_{p} L+R} .
$$

Arm Voltage: Equation (7) contains a nonlinearity consisting of a multiplication between $n_{u}(t)$ and $v_{C u}^{\Sigma}(t)$, which generates frequency components in the arm voltage spectrum according to (26). When calculating a specific perturbation frequency component of $V_{u}(f)$, one must consider all possible combinations of steady-state components and perturbation components of $N_{u}(f)$ and $V_{C u}^{\Sigma}(f)$, through addition and subtraction, that result in the desired frequency component (see Table II). Thus, expressing (7) in the frequency domain using (26) leads to

$$
\begin{aligned}
& V_{u}\left(f_{p}\right)-N_{u}(0) V_{C u}^{\Sigma}\left(f_{p}\right)-N_{u}\left(f_{1}\right) V_{C u}^{\Sigma}\left(f_{1}-f_{p}\right)^{*} \\
& \quad-N_{u}\left(f_{1}\right)^{*} V_{C u}^{\Sigma}\left(f_{1}+f_{p}\right)=V_{C u}^{\Sigma}(0) N_{u}\left(f_{p}\right) \\
& \quad+V_{C u}^{\Sigma}\left(2 f_{1}\right) N_{u}\left(2 f_{1}-f_{p}\right)^{*} .
\end{aligned}
$$

Notice that the perturbation frequency component of interest always result from the product of a steady-state and a perturbation value, meaning that (36) is linear, because the steady-state values are known (see Appendix). 
TABLE II

FREQUENCY-COMPONENT COMBINATIONS; ANALYZED COMPONENTS ARE HighLIGHTED

\begin{tabular}{c|c|c|c|c|c} 
& $-2 f_{1}$ & $-f_{1}$ & 0 & $f_{1}$ & $2 f_{1}$ \\
\hline$f_{p}$ & $-2 f_{1}+f_{p}$ & $-f_{1}+f_{p}$ & $f_{p}$ & $f_{1}+f_{p}$ & $2 f_{1}+f_{p}$ \\
$f_{1}-f_{p}$ & $-f_{1}-f_{p}$ & $-f_{p}$ & $f_{1}-f_{p}$ & $2 f_{1}-f_{p}$ & $3 f_{1}-f_{p}$ \\
$f_{1}+f_{p}$ & $-f_{1}+f_{p}$ & $f_{p}$ & $f_{1}+f_{p}$ & $2 f_{1}+f_{p}$ & $3 f_{1}+f_{p}$ \\
$2 f_{1}-f_{p}$ & $-f_{p}$ & $f_{1}-f_{p}$ & $2 f_{1}-f_{p}$ & $3 f_{1}-f_{p}$ & $4 f_{1}-f_{p}$ \\
$2 f_{1}+f_{p}$ & $f_{p}$ & $f_{1}+f_{p}$ & $2 f_{1}+f_{p}$ & $3 f_{1}+f_{p}$ & $4 f_{1}+f_{p}$ \\
$3 f_{1}-f_{p}$ & $f_{1}-f_{p}$ & $2 f_{1}-f_{p}$ & $3 f_{1}-f_{p}$ & $4 f_{1}-f_{p}$ & $5 f_{1}-f_{p}$ \\
$3 f_{1}+f_{p}$ & $f_{1}+f_{p}$ & $2 f_{1}+f_{p}$ & $3 f_{1}+f_{p}$ & $4 f_{1}+f_{p}$ & $5 f_{1}+f_{p}$ \\
$-f_{p}$ & $-2 f_{1}-f_{p}$ & $-f_{1}-f_{p}$ & $-f_{p}$ & $f_{1}-f_{p}$ & $2 f_{1}-f_{p}$ \\
$-f_{1}+f_{p}$ & $-3 f_{1}+f_{p}$ & $-2 f_{1}+f_{p}$ & $-f_{1}+f_{p}$ & $f_{p}$ & $f_{1}+f_{p}$ \\
$-f_{1}-f_{p}$ & $-3 f_{1}-f_{p}$ & $-2 f_{1}-f_{p}$ & $-f_{1}-f_{p}$ & $-f_{p}$ & $f_{1}-f_{p}$ \\
$-2 f_{1}+f_{p}$ & $-4 f_{1}+f_{p}$ & $-3 f_{1}+f_{p}$ & $-2 f_{1}+f_{p}$ & $-f_{1}+f_{p}$ & $f_{p}$
\end{tabular}

Sum-Capacitor-Voltage: Similarly to the arm voltages, sumcapacitor-voltages also result from a nonlinearity consisting of a multiplication, as shown in (8). Therefore, the same reasoning can be applied when calculating the perturbation frequency components of $V_{C u}^{\Sigma}(f)$, leading to

$$
\begin{aligned}
& V_{C u}^{\Sigma}\left(f_{p}\right)-\frac{1}{j \omega_{p} C}\left[N_{u}(0) I_{u}\left(f_{p}\right)+N_{u}\left(f_{1}\right) I_{u}\left(f_{1}-f_{p}\right)^{*}\right. \\
& \left.\quad+N_{u}\left(f_{1}\right)^{*} I_{u}\left(f_{1}+f_{p}\right)\right]=\frac{1}{j \omega_{p} C}\left[I_{u}(0) N_{u}\left(f_{p}\right)\right. \\
& \left.\quad+I_{u}\left(2 f_{1}\right) N_{u}\left(2 f_{1}-f_{p}\right)^{*}\right]
\end{aligned}
$$

AC-Side Admittance: Equations (35)-(37) and (43)-(60) consist of a linear system of the form

$$
A_{p} \mathbf{x}_{p}=B_{p},
$$

with 21 equations and the 21 unknown variables

$$
\begin{aligned}
\mathbf{x}_{p}= & {\left[I_{u}\left(f_{p}\right), I_{u}\left(f_{1}-f_{p}\right), I_{u}\left(f_{1}+f_{p}\right), I_{u}\left(2 f_{1}-f_{p}\right),\right.} \\
& I_{u}\left(2 f_{1}+f_{p}\right), I_{u}\left(3 f_{1}-f_{p}\right), I_{u}\left(3 f_{1}+f_{p}\right), \\
& V_{u}\left(f_{p}\right), V_{u}\left(f_{1}-f_{p}\right), V_{u}\left(f_{1}+f_{p}\right), V_{u}\left(2 f_{1}-f_{p}\right), \\
& V_{u}\left(2 f_{1}+f_{p}\right), V_{u}\left(3 f_{1}-f_{p}\right), V_{u}\left(3 f_{1}+f_{p}\right), \\
& V_{C u}^{\Sigma}\left(f_{p}\right), V_{C u}^{\Sigma}\left(f_{1}-f_{p}\right), V_{C u}^{\Sigma}\left(f_{1}+f_{p}\right), V_{C u}^{\Sigma}\left(2 f_{1}-f_{p}\right), \\
& \left.V_{C u}^{\Sigma}\left(2 f_{1}+f_{p}\right), V_{C u}^{\Sigma}\left(3 f_{1}-f_{p}\right), V_{C u}^{\Sigma}\left(3 f_{1}+f_{p}\right)\right]^{T} .
\end{aligned}
$$

The matrix $A_{p}$ contains the coefficients of the linear system, while the vector $B_{p}$ contains the constants terms, which are related to the applied perturbation $E\left(f_{p}\right)$. For example, (35) yields

$$
\begin{aligned}
& A(1,1)=1 \quad A(1,8)=\frac{1}{j \omega_{p} L+R} \\
& B(1)=-\frac{E\left(f_{p}\right)}{j \omega_{p} L+R} .
\end{aligned}
$$

Notably, the steady-state values of the converter variables are known (see Appendix); therefore, they are included into $A_{p}$ and $B_{p}$.

The linear system (38) can be solved to obtain the perturbation solution of arm current, arm voltage, and sum-capacitorvoltage. From this solution, $I_{u}\left(f_{p}\right)$ is used to obtain the ac-side admittance, as the ac-side current can be expressed as

$$
I_{s}\left(f_{p}\right)=I_{u}\left(f_{p}\right)-I_{l}\left(f_{p}\right)=2 I_{u}\left(f_{p}\right),
$$

due to the inherent symmetries of the MMC topology. Therefore, using (19), we obtain

$$
Y_{a c}\left(f_{p}\right)=-\frac{2 I_{u}\left(f_{p}\right)}{E\left(f_{p}\right)} .
$$

This expression can be extended for to an arbitrary frequency, i.e., $f_{p} \rightarrow f$, matching the definition (19).

Remark: The focus of this paper is on the method used to derive the ac-side admittance of MMCs. When MMCs are operated in a different way than described in this study, e.g., with a different control strategy or with a different network at the dc side, the analysis presented in this section needs to be adjusted accordingly. For example, operating the MMC with current control makes the insertion index linearly dependent on the arm current through the current-controller transfer function. Consequently, perturbation frequency components appear in the insertion index spectrum, which need to be included into $\mathbf{x}_{p}$. The effect of these additional frequency components on arm voltages and sum-capacitor-voltages can be added into the analysis similarly to how $N\left(f_{p}\right)$ is included into (36) and (37), i.e., as linear combination of steadystate and perturbation frequency components of the converter variables. An exhaustive assessment of the impact of different control strategies on the ac-side admittance will be covered in future studies.

\section{VERIFICATION}

The validation of this study is made in two parts. Firstly, SIMULINK simulations are used to evaluate how the method outlined in Section III performs in relation to the timeaveraged model described in Section II. Then, experiments on a down-scaled prototype are used to assess the validity of this study, and the simplifications on which it is based, in relation to a real MMC.

\section{A. Simulation Results}

The MMC time-averaged model described in Section II is implemented in SIMULINK, using the parameters of the experimental setup, listed in Table III. In order to measure the ac-side admittance, the system is simulated multiple times, sweeping the perturbation frequency through the desired range. At every iteration, the current $I_{s}\left(f_{p}\right)$, produced by the voltage $E\left(f_{p}\right)$, is measured using MATLAB's fast Fourier transform algorithm and the admittance is calculated using (19).

The admittance plot resulting from simulations is compared with the analytical model outlined in Section III, which is evaluated for different degrees of accuracy. Namely, the model is firstly evaluated excluding the impact of the PLL and calculating only two perturbation frequency components $\left(f_{p}\right.$ and $f_{1}+f_{p}$ ), then calculating three perturbation frequency components $\left(f_{p}, f_{1}-f_{p}\right.$, and $\left.f_{1}+f_{p}\right)$, and finally including the impact of the PLL and calculating all the seven perturbation frequency components listed in Table I. The result of this comparison is presented in Fig. 6, which shows that, 

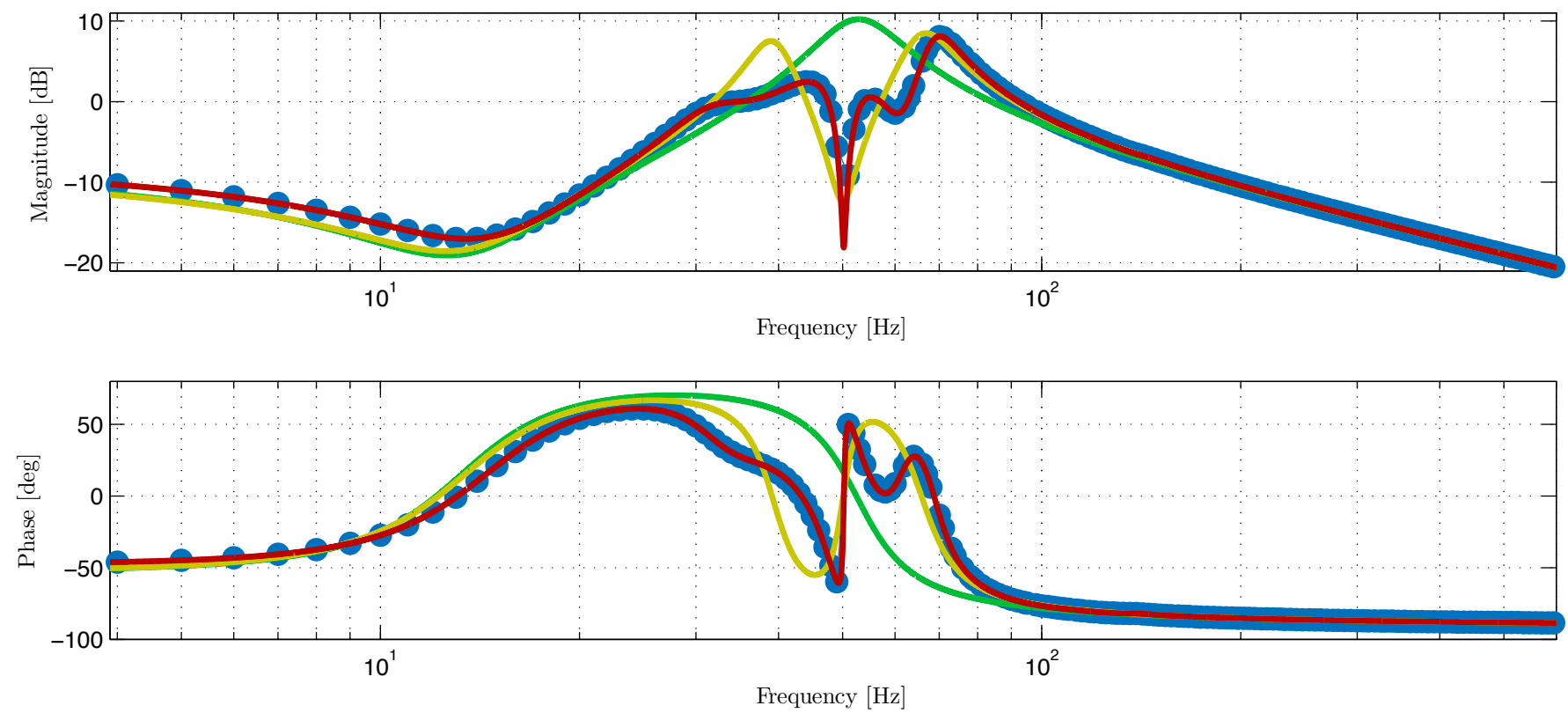

Fig. 6. Bode diagram of the MMC ac-side admittance: SIMULINK simulations (blue dots); lowest-order analytical model, i.e., no PLL impact and only two perturbation frequency components (green line); mid-order analytical model, i.e., no PLL impact and only three perturbation frequency components (yellow line); highest-order analytical model, i.e., including PLL impact and all seven perturbation frequency components (red line).

TABLE III

MMC PARAMETERS - SimULATION AND EXPERIMENT

\begin{tabular}{l|l|ll}
\hline PCC voltage amplitude & $e_{1}$ & $48 \mathrm{~V}$ \\
Fundamental frequency & $f_{1}$ & $50 \mathrm{~Hz}$ & \\
Arm inductance & $L$ & $5.7 \mathrm{mH}$ & \\
Arm resistance & $R$ & $0.55 \Omega$ & \\
Arm capacitance & $C$ & $0.54 \mathrm{mF}$ & \\
Resistive load & $R_{d}$ & $25 \Omega$ & \\
Modulation index & $m_{1}$ & 0.9 & \\
PLL bandwidth & $\alpha_{p}$ & $25 \mathrm{rad} / \mathrm{s}$ & \\
PLL low-pass filter & $\omega_{f}$ & $250 \mathrm{rad} / \mathrm{s}$ & \\
Perturbation amplitude & $e_{p}$ & $0.8 \mathrm{~V}$ & \\
Submodules per arm & $N$ & 5 & (experiment only) \\
Carrier frequency & $f_{c}$ & $763 \mathrm{~Hz}$ & (experiment only) \\
\hline
\end{tabular}

evidently, the accuracy of the analytical model improves as more perturbation terms are added to it. The lowest-order model can capture the admittance qualitative behavior; then, the mid-order model shows an improved fit, especially around the fundamental frequency; finally, the highest-order model shows an excellent fit at all frequencies. Judging which order is the most appropriate ultimately depends on the application for which the admittance model is required.

Observation: As seen throughout Section III-B, a single perturbation term in the PCC voltage generates multiple frequency components in the converter variables, due to the nonlinearity of the MMC internal dynamics. Solving the linear system (38) not only allows obtaining the expression of the ac-side admittance, but also provides the values of all the main perturbation frequency components in the converter variables produced by $E\left(f_{p}\right)$. As an example, Fig. 7 shows

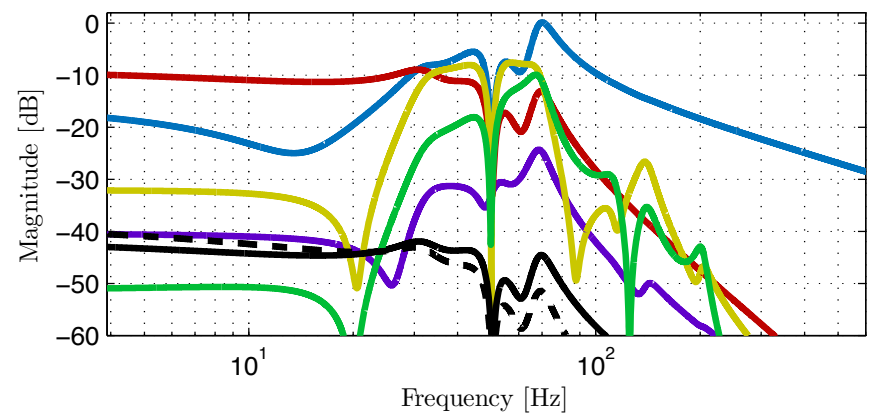

Fig. 7. Magnitude of the perturbation frequency components of the arm current generated by $E\left(f_{p}\right): I_{u}\left(f_{p}\right)$ (blue line); $I_{u}\left(f_{1}-f_{p}\right)$ (purple line); $I_{u}\left(f_{1}+f_{p}\right)$ (red line); $I_{u}\left(2 f_{1}-f_{p}\right)$ (yellow line); $I_{u}\left(2 f_{1}+f_{p}\right)$ (black line); $I_{u}\left(3 f_{1}-f_{p}\right)$ (green line); $I_{u}\left(3 f_{1}+f_{p}\right)$ (dashed black line).

the magnitude of the perturbation frequency components in the arm current generated by $E\left(f_{p}\right)$, giving an insight on the impact that each frequency component has.

\section{B. Experimental Results}

The down-scaled MMC prototype used for experimental verification employs five full-bridge submodules per arm, i.e., a total of 30 submodules, and has a rated power of $10 \mathrm{~kW}$. The control system is based on Xilinx Zynq-7000 system on chip, which integrates a processing system with a programmable logic. The programmable logic performs low-level control, i.e., communication with the submodules and phase-shifted carriers modulation, which ensures the balancing of the individual capacitor voltages within the arm [32]. The processing system performs high-level control, such as insertion indices computation, PLL, and a MATLAB-based graphic user interface. 




Fig. 8. Configuration of the experimental setup for MMC ac-side admittance measurement.

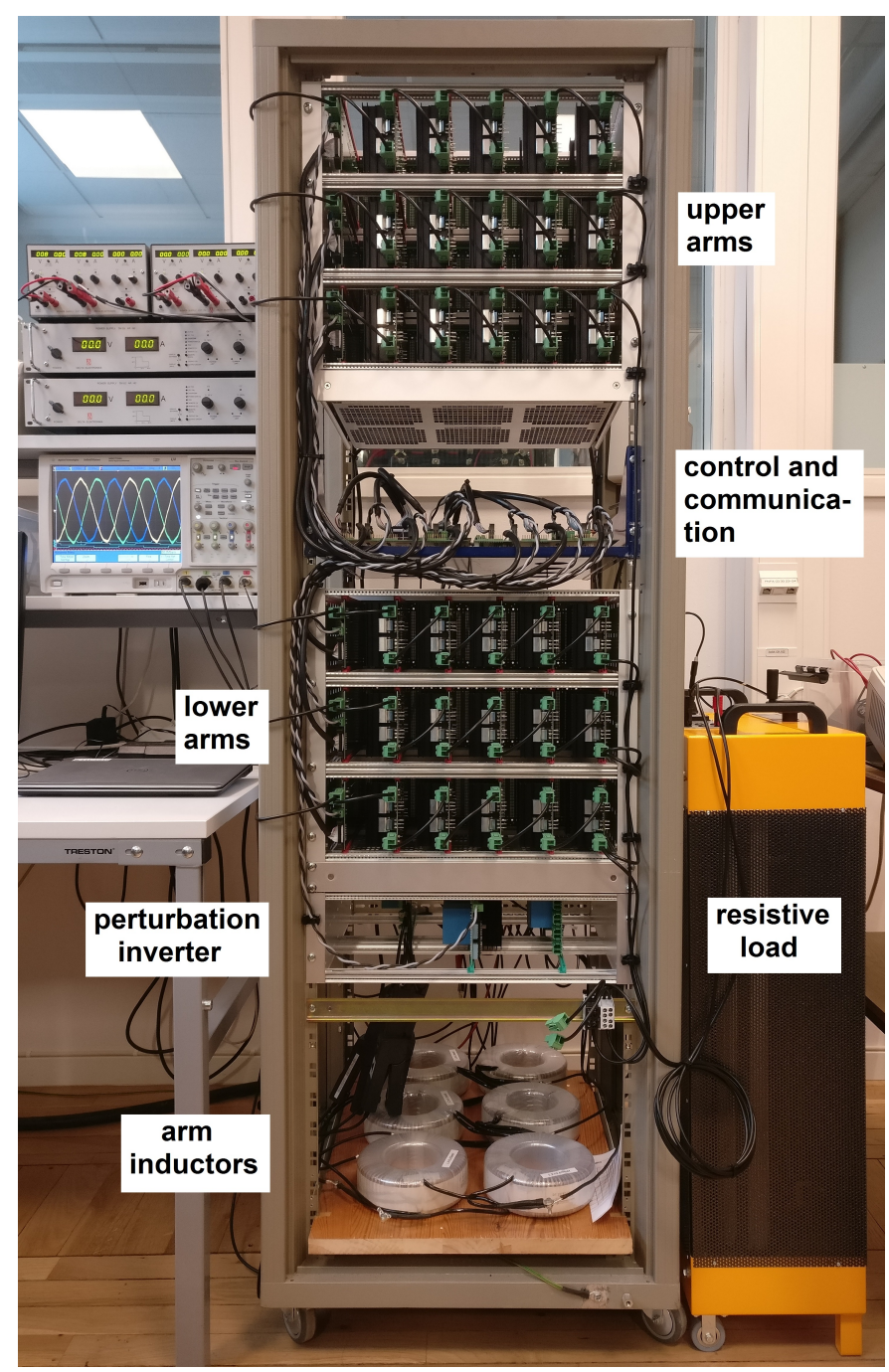

Fig. 9. Photograph of the experimental setup.

The experiment is designed as follows. The device under test, i.e., the MMC prototype, is connected at the PCC to a two-level inverter, which is designed to generate a perturbation term $\tilde{e}(t)$ superimposed onto the fundamental-frequency threephase voltage $e(t)$. In the experiment, the MMC is operated with fixed sinusoidal modulation pattern, as shown in Fig. 3. The system configuration of the experimental setup is shown in Fig. 8, with a photograph in Fig. 9, and Table IV lists the specifications of the perturbation inverter. The PCC voltage
TABLE IV

PERTURBATION INVERTER PARAMETERS

\begin{tabular}{l|l|l}
\hline DC side voltage & $V_{d c}$ & $105 \mathrm{~V}$ \\
PCC voltage amplitude & $e_{1}$ & $48 \mathrm{~V}$ \\
Fundamental frequency & $f_{1}$ & $50 \mathrm{~Hz}$ \\
Perturbation amplitude & $e_{p}$ & $0.8 \mathrm{~V}$ \\
Perturbation frequency & $f_{p}$ & $2 \mathrm{~Hz}-2 \mathrm{kHz}$ \\
Switching frequency & $f_{s w}$ & $24 \mathrm{kHz}$ \\
LC filter resonant frequency & $f_{L C}$ & $4.1 \mathrm{kHz}$ \\
\hline
\end{tabular}

$e(t)$ and the ac-side current $i_{s}(t)$ are measured using the data acquisition system of the prototype, exported in MATLAB, and analyzed in the frequency domain (using the discrete Fourier transform) to extract the ac-side admittance of the prototype at $f_{p}$ using the definition (19). This operation is iterated, sweeping the perturbation frequency through the desired range to obtain Fig. 10, showing the frequency-domain plot of the admittance. Fig. 11 and Fig. 12 show two examples of the waveforms of the converter variables during the experiment, with $f_{p}=406 \mathrm{~Hz}$ and $f_{p}=4 \mathrm{~Hz}$. In these figures, the amplitude of the perturbation is increased to $e_{p}=3.5 \mathrm{~V}$, in order to make the perturbation visible in the time domain. However, $e_{p}$ should be small compared to $e_{1}$ (see assumption 20 ), because harmonic linearization is based on small-signal modeling.

The admittance plot resulting from experiments is compared with the highest-order analytical model derived in Section III. The result of this comparison, presented in Fig. 10, shows remarkable agreement between the two curves in the whole frequency range. This agreement validates the developed analytical model and allows to conclude that using the MMC time-averaged model, which neglects the switching operations and the individual capacitor-voltage dynamics, does not compromise the validity of this study.

Observation: In order to produce accurate results, the MMC parameters $L, R$, and $C$ need to be known with good precision. In typical MMC applications, $R$ is the only parameter subject to variations. Fortunately, as MMCs are designed for high efficiency, $R$ is normally small. Hence, imprecise values of $R$ are also acceptable, as the predominant contributors in shaping the MMC ac-side admittance are $L$ and $C$.

\section{CONClusion}

In this paper, a method for calculating ac-side admittance of MMCs is presented. The nonlinearities introduced by the MMC internal dynamics and the PLL are included in the model and are handled using linearization in the frequency domain. Through simulations and experiments, the proposed method is verified, confirming the validity of this study and the simplifications on which it is based. The tradeoff posed by complexity of the method and accuracy of the results is discussed, concluding that the optimal choice ultimately depends on the application. Furthermore, it is shown that, in addition to the ac-side admittance, the proposed method shows in detail how a perturbation frequency component in the PCC voltage affects the spectra of the converter variables, which provides additional useful insight. 


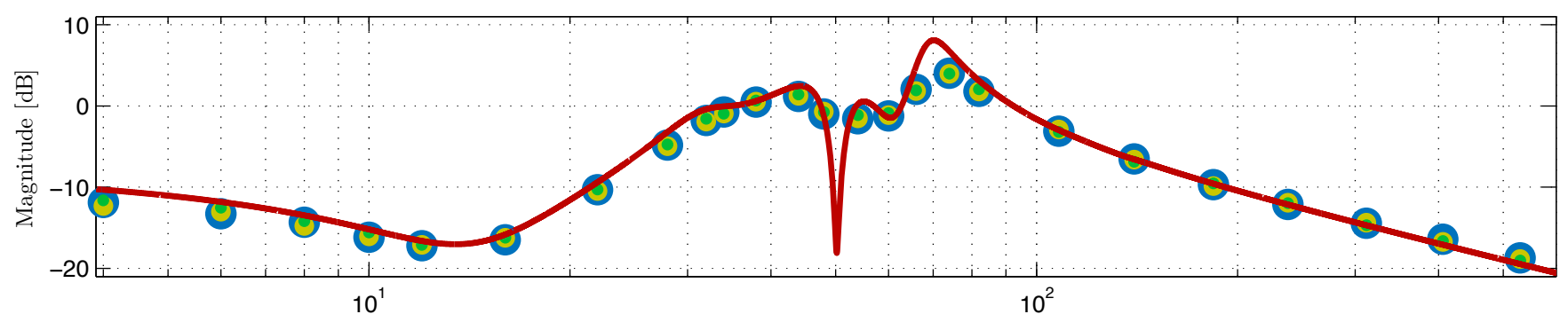

Frequency $[\mathrm{Hz}]$



Fig. 10. Bode diagram of the MMC ac-side admittance: measurements on a MMC down-scaled prototype, phase $a$ (blue dots), phase $b$ (yellow dots), and phase $c$ (green dots); analytical model (red line).

The method proposed in this paper provides foundation for future work, which will focus on evaluating the impact of different control strategies on the ac-side admittance, offering useful design tools for analyzing grid-converter interaction and designing the system.

\section{APPENDIX}

\section{A. Perturbation Solution}

The linear expressions describing arm current, arm voltage, and sum-capacitor-voltage at $f_{1} \pm f_{p}, 2 f_{1} \pm f_{p}$, and $3 f_{1} \pm f_{p}$ are given in this subsection.

Arm Current: The following expressions are obtained similarly to (35).

$$
\begin{gathered}
I_{u}\left(f_{1}-f_{p}\right)+\frac{V_{u}\left(f_{1}-f_{p}\right)}{j\left(\omega_{1}-\omega_{p}\right) L+R+\frac{3}{2} R_{d}}=0 \\
I_{u}\left(f_{1}+f_{p}\right)+\frac{V_{u}\left(f_{1}+f_{p}\right)}{j\left(\omega_{1}+\omega_{p}\right) L+R}=0 \\
I_{u}\left(2 f_{1}-f_{p}\right)+\frac{V_{u}\left(2 f_{1}-f_{p}\right)}{j\left(2 \omega_{1}-\omega_{p}\right) L+R}=0 \\
I_{u}\left(2 f_{1}+f_{p}\right)+\frac{V_{u}\left(2 f_{1}+f_{p}\right)}{j\left(2 \omega_{1}+\omega_{p}\right) L+R+\frac{3}{2} R_{d}}=0 \\
I_{u}\left(3 f_{1}-f_{p}\right)+\frac{V_{u}\left(3 f_{1}-f_{p}\right)}{j\left(3 \omega_{1}-\omega_{p}\right) L+R}=0 \\
I_{u}\left(3 f_{1}+f_{p}\right)+\frac{V_{u}\left(3 f_{1}+f_{p}\right)}{j\left(3 \omega_{1}+\omega_{p}\right) L+R}=0 .
\end{gathered}
$$

Notably, (43) and (46) include the term $3 / 2 R_{d}$, as zerosequence components of the arm current flow into the load.
Arm Voltage: The following expressions are obtained similarly to (36).

$$
\begin{aligned}
& V_{u}\left(f_{1}-f_{p}\right)-N_{u}(0) V_{C u}^{\Sigma}\left(f_{1}-f_{p}\right)-N_{u}\left(f_{1}\right) V_{C u}^{\Sigma}\left(f_{p}\right)^{*} \\
& \quad-N_{u}\left(f_{1}\right)^{*} V_{C u}^{\Sigma}\left(2 f_{1}-f_{p}\right)=V_{C u}^{\Sigma}\left(f_{1}\right) N_{u}\left(f_{p}\right)^{*} \\
& +V_{C u}^{\Sigma}\left(f_{1}\right)^{*} N_{u}\left(2 f_{1}-f_{p}\right) \\
& V_{u}\left(f_{1}+f_{p}\right)-N_{u}(0) V_{C u}^{\Sigma}\left(f_{1}+f_{p}\right)-N_{u}\left(f_{1}\right) V_{C u}^{\Sigma}\left(f_{p}\right) \\
& \quad-N_{u}\left(f_{1}\right)^{*} V_{C u}^{\Sigma}\left(2 f_{1}+f_{p}\right)=V_{C u}^{\Sigma}\left(f_{1}\right) N_{u}\left(f_{p}\right) \\
& V_{u}\left(2 f_{1}-f_{p}\right)-N_{u}(0) V_{C u}^{\Sigma}\left(2 f_{1}-f_{p}\right) \\
& \quad-N_{u}\left(f_{1}\right) V_{C u}^{\Sigma}\left(f_{1}-f_{p}\right)-N_{u}\left(f_{1}\right)^{*} V_{C u}^{\Sigma}\left(3 f_{1}-f_{p}\right) \\
& =V_{C u}^{\Sigma}(0) N_{u}\left(2 f_{1}-f_{p}\right)+V_{C u}^{\Sigma}\left(2 f_{1}\right) N_{u}\left(f_{p}\right)^{*} \\
& V_{u}\left(2 f_{1}+f_{p}\right)-N_{u}(0) V_{C u}^{\Sigma}\left(2 f_{1}+f_{p}\right) \\
& \quad-N_{u}\left(f_{1}\right) V_{C u}^{\Sigma}\left(f_{1}+f_{p}\right)-N_{u}\left(f_{1}\right)^{*} V_{C u}^{\Sigma}\left(3 f_{1}+f_{p}\right) \\
& =V_{C u}^{\Sigma}\left(2 f_{1}\right) N_{u}\left(f_{p}\right) \\
& V_{u}\left(3 f_{1}-f_{p}\right)-N_{u}(0) V_{C u}^{\Sigma}\left(3 f_{1}-f_{p}\right) \\
& -N_{u}\left(f_{1}\right) V_{C u}^{\Sigma}\left(2 f_{1}-f_{p}\right)=V_{C u}^{\Sigma}\left(f_{1}\right) N_{u}\left(2 f_{1}-f_{p}\right) \\
& \quad V_{u}\left(3 f_{1}+f_{p}\right)-N_{u}(0) V_{C u}^{\Sigma}\left(3 f_{1}+f_{p}\right) \\
& \quad-N_{u}\left(f_{1}\right) V_{C u}^{\Sigma}\left(2 f_{1}+f_{p}\right)=0 .
\end{aligned}
$$

Sum-Capacitor-Voltage: The following expressions are obtained similarly to (37).

$$
\begin{aligned}
& V_{C u}^{\Sigma}\left(f_{1}-f_{p}\right)-\frac{1}{j\left(\omega_{1}-\omega_{p}\right) C}\left[N_{u}(0) I_{u}\left(f_{1}-f_{p}\right)\right. \\
& \left.\quad+N_{u}\left(f_{1}\right) I_{u}\left(f_{p}\right)^{*}+N_{u}\left(f_{1}\right)^{*} I_{u}\left(2 f_{1}-f_{p}\right)\right] \\
& \quad=\frac{1}{j\left(\omega_{1}-\omega_{p}\right) C}\left[I_{u}\left(f_{1}\right) N_{u}\left(f_{p}\right)^{*}+I_{u}\left(f_{1}\right)^{*} N_{u}\left(2 f_{1}-f_{p}\right)\right]
\end{aligned}
$$



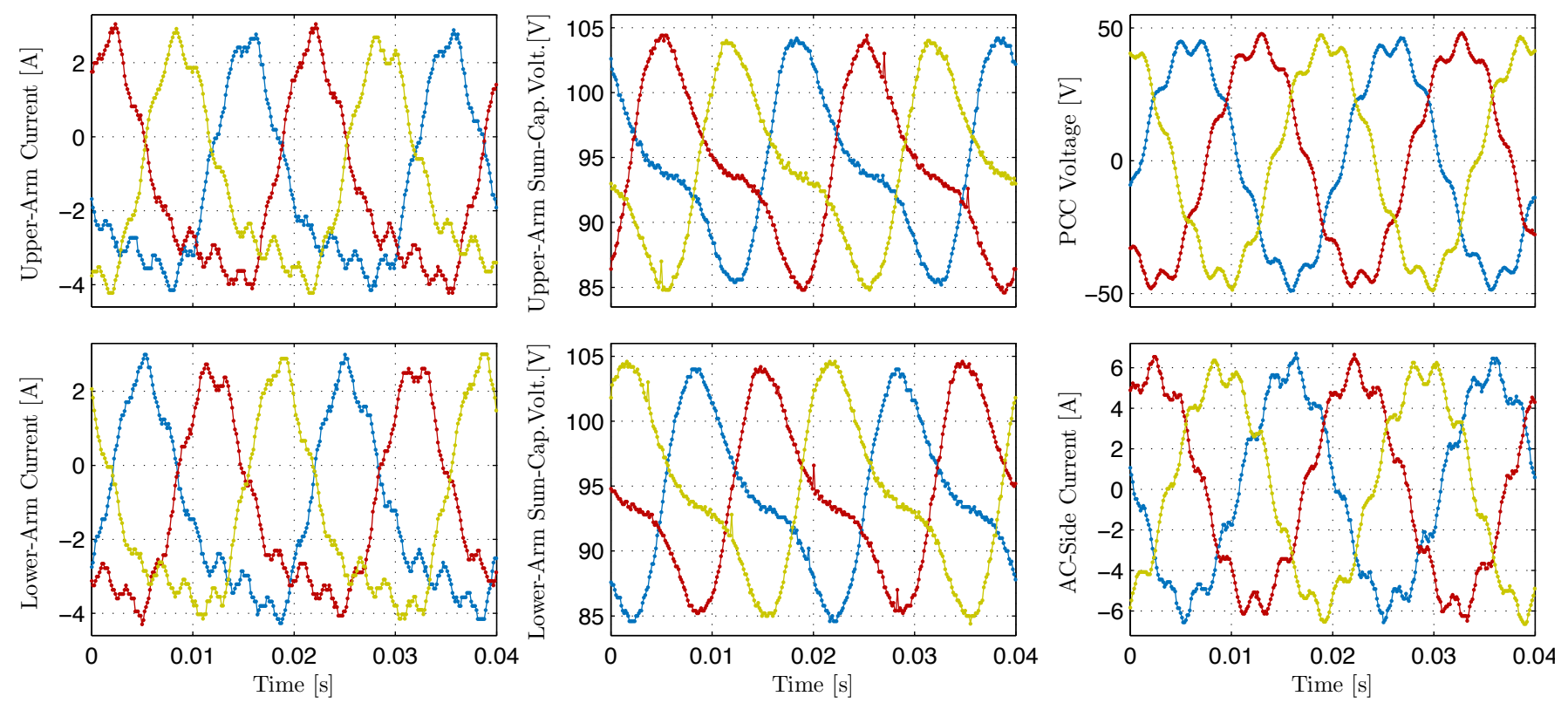

Fig. 11. Waveforms of the converter variables during the experiment at $f_{p}=406 \mathrm{~Hz}$ : upper- and lower-arm currents (left); upper- and lower-arm sumcapacitor-voltages (center); PCC voltage (upper-right); ac-side current (lower-right). Three-phase waveforms are shown: phase $a$ (blue), phase $b$ (red), and phase $c$ (yellow).

$$
\begin{aligned}
& V_{C u}^{\Sigma}\left(f_{1}+f_{p}\right)-\frac{1}{j\left(\omega_{1}+\omega_{p}\right) C}\left[N_{u}(0) I_{u}\left(f_{1}+f_{p}\right)\right. \\
& \left.\quad+N_{u}\left(f_{1}\right) I_{u}\left(f_{p}\right)+N_{u}\left(f_{1}\right)^{*} I_{u}\left(2 f_{1}+f_{p}\right)\right] \\
& \quad=\frac{I_{u}\left(f_{1}\right) N_{u}\left(f_{p}\right)}{j\left(\omega_{1}+\omega_{p}\right) C}
\end{aligned}
$$

$$
\begin{aligned}
& V_{C u}^{\Sigma}\left(2 f_{1}-f_{p}\right)-\frac{1}{j\left(2 \omega_{1}-\omega_{p}\right) C}\left[N_{u}(0) I_{u}\left(2 f_{1}-f_{p}\right)\right. \\
& \left.\quad+N_{u}\left(f_{1}\right) I_{u}\left(f_{1}-f_{p}\right)+N_{u}\left(f_{1}\right)^{*} I_{u}\left(3 f_{1}-f_{p}\right)\right] \\
& \quad=\frac{1}{j\left(2 \omega_{1}-\omega_{p}\right) C}\left[I_{u}(0) N_{u}\left(2 f_{1}-f_{p}\right)+I_{u}\left(2 f_{1}\right) N_{u}\left(f_{p}\right)^{*}\right]
\end{aligned}
$$

$$
\begin{aligned}
& V_{C u}^{\Sigma}\left(2 f_{1}+f_{p}\right)-\frac{1}{j\left(2 \omega_{1}+\omega_{p}\right) C}\left[N_{u}(0) I_{u}\left(2 f_{1}+f_{p}\right)\right. \\
& \left.\quad+N_{u}\left(f_{1}\right) I_{u}\left(f_{1}+f_{p}\right)+N_{u}\left(f_{1}\right)^{*} I_{u}\left(3 f_{1}+f_{p}\right)\right] \\
& \quad=\frac{I_{u}\left(2 f_{1}\right) N_{u}\left(f_{p}\right)}{j\left(2 \omega_{1}+\omega_{p}\right) C}
\end{aligned}
$$

$$
\begin{gathered}
V_{C u}^{\Sigma}\left(3 f_{1}-f_{p}\right)-\frac{1}{j\left(3 \omega_{1}-\omega_{p}\right) C}\left[N_{u}(0) I_{u}\left(3 f_{1}-f_{p}\right)\right. \\
\left.+N_{u}\left(f_{1}\right) I_{u}\left(2 f_{1}-f_{p}\right)\right]=\frac{I_{u}\left(f_{1}\right) N_{u}\left(2 f_{1}-f_{p}\right)}{j\left(3 \omega_{1}-\omega_{p}\right) C}
\end{gathered}
$$

$$
\begin{aligned}
& V_{C u}^{\Sigma}\left(3 f_{1}+f_{p}\right)-\frac{1}{j\left(3 \omega_{1}+\omega_{p}\right) C}\left[N_{u}(0) I_{u}\left(3 f_{1}+f_{p}\right)\right. \\
& \left.\quad+N_{u}\left(f_{1}\right) I_{u}\left(2 f_{1}+f_{p}\right)\right]=0 .
\end{aligned}
$$

\section{B. Steady-State Solution}

Insertion Index: The MMC is operated with fixed sinusoidal modulation pattern as (9), which can be expressed in the frequency domain, using (23), as

$$
\begin{aligned}
& N_{u}(0)=\frac{1}{2} \\
& N_{u}\left(f_{1}\right)=-\frac{m_{1}}{4} .
\end{aligned}
$$

Arm Current: Due to the MMC topology, only the zerosequence component of the arm current flows into the dc-side load, i.e., $V_{d u}(f)=V_{d u}(0)=-3 / 2 R_{d} I_{u}(0)$. The steady-state arm current is obtained from (3) as

$$
\begin{aligned}
& I_{u}(0)+\frac{V_{u}(0)}{\frac{3}{2} R_{d}+R}=0 \\
& I_{u}\left(f_{1}\right)+\frac{V_{u}\left(f_{1}\right)}{j \omega_{1} L+R}=-\frac{E\left(f_{1}\right)}{j \omega_{1} L+R} \\
& I_{u}\left(2 f_{1}\right)+\frac{V_{u}\left(2 f_{1}\right)}{j 2 \omega_{1} L+R}=0,
\end{aligned}
$$

where $E\left(f_{1}\right)=e_{1} / 2$ from (2) and (23).

Arm Voltage: Expressing (7) in the frequency domain using (26) leads to

$$
\begin{aligned}
& V_{u}(0)-N_{u}(0) V_{C u}^{\Sigma}(0)-\operatorname{Re}\left[N_{u}\left(f_{1}\right) V_{C u}^{\Sigma}\left(f_{1}\right)^{*}\right]=0 \\
& V_{u}\left(f_{1}\right)-N_{u}(0) V_{C u}^{\Sigma}\left(f_{1}\right)-N_{u}\left(f_{1}\right) V_{C u}^{\Sigma}(0) \\
& \quad-N_{u}\left(f_{1}\right)^{*} V_{C u}^{\Sigma}\left(2 f_{1}\right)=0 \\
& V_{u}\left(2 f_{1}\right)-N_{u}(0) V_{C u}^{\Sigma}\left(2 f_{1}\right)-N_{u}\left(f_{1}\right) V_{C u}^{\Sigma}\left(f_{1}\right)=0 .
\end{aligned}
$$



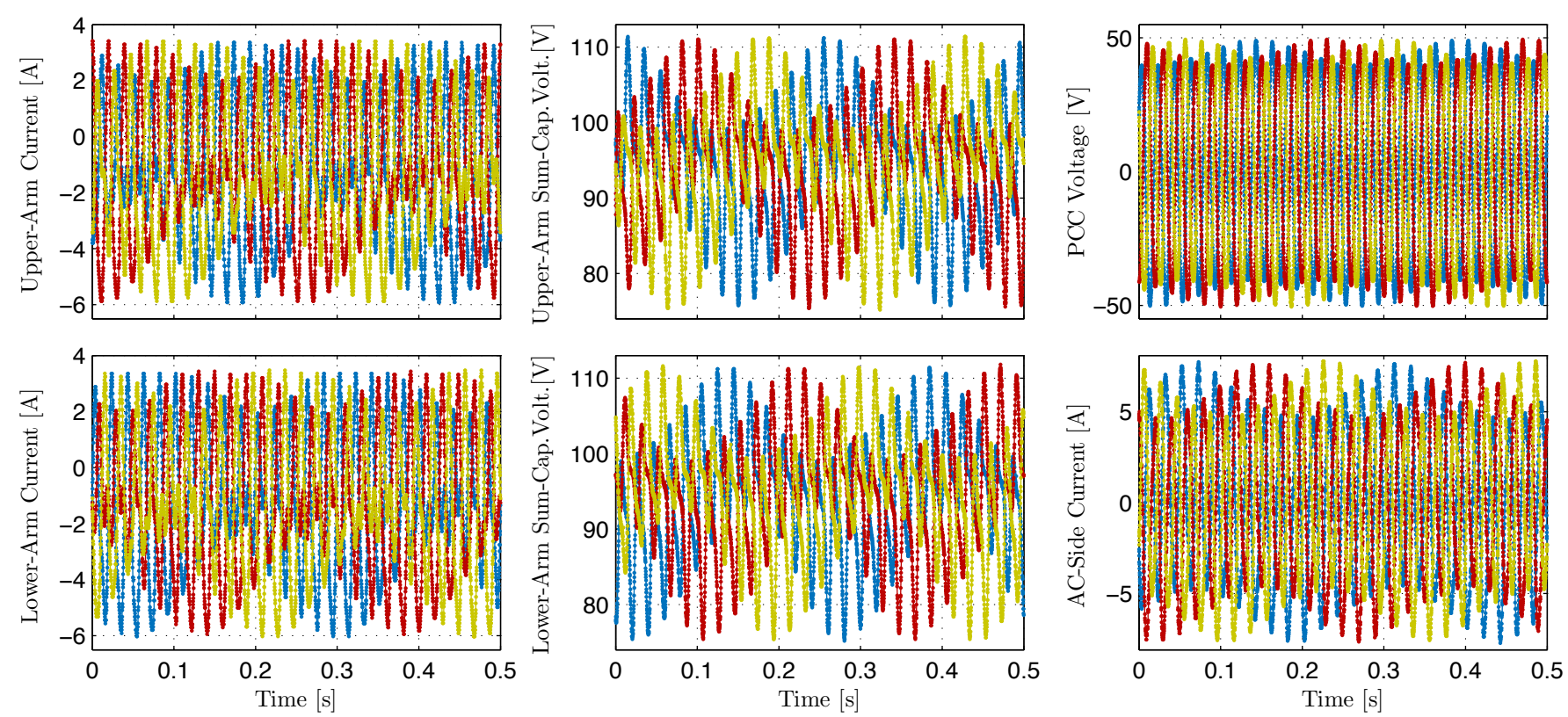

Fig. 12. Waveforms of the converter variables during the experiment at $f_{p}=4 \mathrm{~Hz}$ : upper- and lower-arm currents (left); upper- and lower-arm sum-capacitorvoltages (center); PCC voltage (upper-right); ac-side current (lower-right). Three-phase waveforms are shown: phase $a$ (blue), phase $b$ (red), and phase $c$ (yellow).

Sum-Capacitor-Voltage: Expressing (8) in the frequency domain using (26) leads to

$$
\begin{aligned}
& N_{u}(0) I_{u}(0)+\operatorname{Re}\left[N_{u}\left(f_{1}\right) I_{u}\left(f_{1}\right)^{*}\right]=0 \\
& V_{C u}^{\Sigma}\left(f_{1}\right)-\frac{1}{j \omega_{1} C}\left[N_{u}(0) I_{u}\left(f_{1}\right)+N_{u}\left(f_{1}\right) I_{u}(0)\right. \\
& \left.\quad+N_{u}\left(f_{1}\right)^{*} I_{u}\left(2 f_{1}\right)\right]=0 \\
& V_{C u}^{\Sigma}\left(2 f_{1}\right)-\frac{1}{j 2 \omega_{1} C}\left[N_{u}(0) I_{u}\left(2 f_{1}\right)+N_{u}\left(f_{1}\right) I_{u}\left(f_{1}\right)\right]=0
\end{aligned}
$$

where (69) is written using (8) with the constraint that the product $i_{u}(t) n_{u}(t)$ has zero dc component.

Solution: Equations (63)-(71) consist of a linear system of the form

$$
A_{s} \mathbf{x}_{s}=B_{s},
$$

with 9 equations and the 9 unknown variables

$$
\begin{aligned}
\mathbf{x}_{s}=[ & I_{u}(0), I_{u}\left(f_{1}\right), I_{u}\left(2 f_{1}\right), V_{u}(0), V_{u}\left(f_{1}\right), \\
& \left.V_{u}\left(2 f_{1}\right), V_{C u}^{\Sigma}(0), V_{C u}^{\Sigma}\left(f_{1}\right), V_{C u}^{\Sigma}\left(2 f_{1}\right)\right]^{T} .
\end{aligned}
$$

The linear system (72) can be solved to obtain the steadystate solution of arm current, arm voltage, and sum-capacitorvoltage.

\section{REFERENCES}

[1] A. Lesnicar and R. Marquardt, "An innovative modular multilevel converter topology suitable for a wide power range," in Power Tech Conf. Proc., Bologna, Italy, 2003.

[2] S. Allebrod, R. Hamerski, and R. Marquardt, "New transformerless, scalable modular multilevel converters for HVDC-transmission," in 2008 IEEE Power Electron. Spec. Conf. IEEE, Jun. 2008, pp. 174-179.

[3] H. Akagi, "Classification, terminology, and application of the modular multilevel cascade converter (MMCC)," IEEE Trans. Power Electron., vol. 26, no. 11, pp. 3119-3130, Nov. 2011.
[4] S. Debnath, J. Qin, B. Bahrani, M. Saeedifard, and P. Barbosa, "Operation, control, and applications of the modular multilevel converter: A review," IEEE Trans. Power Electron., vol. 30, no. 1, pp. 37-53, Jan. 2015.

[5] M. A. Perez, S. Bernet, J. Rodriguez, S. Kouro, and R. Lizana, "Circuit topologies, modeling, control schemes, and applications of modular multilevel converters," IEEE Trans. Power Electron., vol. 30, no. 1, pp. 4-17, Jan. 2015.

[6] M. Glinka and R. Marquardt, "A new ac/ac multilevel converter family," IEEE Trans. Ind. Electron., vol. 52, no. 3, pp. 662-669, Jun. 2005.

[7] M. Saeedifard and R. Iravani, "Dynamic performance of a modular multilevel back-to-back HVDC system," IEEE Trans. Power Deliv. vol. 25, no. 4, pp. 2903-2912, Oct. 2010.

[8] L. Harnefors, A. Antonopoulos, S. Norrga, L. Angquist, and H.-P. Nee, "Dynamic analysis of modular multilevel converters," IEEE Trans. Ind. Electron., vol. 60, no. 7, pp. 2526-2537, Jul. 2013.

[9] M. Hagiwara and H. Akagi, "Control and experiment of pulsewidthmodulated modular multilevel converters," IEEE Trans. Power Electron., vol. 24, no. 7, pp. 1737-1746, Jul. 2009.

[10] M. Hagiwara, R. Maeda, and H. Akagi, "Control and analysis of the modular multilevel cascade converter based on double-star choppercells (MMCC-DSCC)," IEEE Trans. Power Electron., vol. 26, no. 6, pp. 1649-1658, Jun. 2011.

[11] S. Rohner, S. Bernet, M. Hiller, and R. Sommer, "Modulation, losses, and semiconductor requirements of modular multilevel converters," IEEE Trans. Ind. Electron., vol. 57, no. 8, pp. 2633-2642, Aug. 2010.

[12] Q. Tu, Z. Xu, and L. Xu, "Reduced switching-frequency modulation and circulating current suppression for modular multilevel converters," IEEE Trans. Power Deliv., vol. 26, no. 3, pp. 2009-2017, Jul. 2011.

[13] K. Ilves, A. Antonopoulos, S. Norrga, and H.-P. Nee, "Steady-state analysis of interaction between harmonic components of arm and line quantities of modular multilevel converters," IEEE Trans. Power Electron., vol. 27, no. 1, pp. 57-68, Jan. 2012.

[14] Q. Song, W. Liu, X. Li, H. Rao, S. Xu, and L. Li, “A steady-state analysis method for a modular multilevel converter," IEEE Trans. Power Electron., vol. 28, no. 8, pp. 3702-3713, Aug. 2013.

[15] M. Guan and Z. Xu, "Modeling and control of a modular multilevel converter-based HVDC system under unbalanced grid conditions," IEEE Trans. Power Electron., vol. 27, no. 12, pp. 4858-4867, Dec. 2012.

[16] A. Nami, J. Liang, F. Dijkhuizen, and G. D. Demetriades, "Modular multilevel converters for HVDC applications: Review on converter cells and functionalities," IEEE Trans. Power Electron., vol. 30, no. 1, pp. 18-36, Jan. 2015. 
[17] J. Sun, "Impedance-based stability criterion for grid-connected inverters," IEEE Trans. Power Electron., vol. 26, no. 11, pp. 3075-3078, Nov. 2011.

[18] L. Harnefors, X. Wang, A. G. Yepes, and F. Blaabjerg, "Passivity-based stability assessment of grid-connected VSCs-An overview," IEEE J. Emerg. Sel. Top. Power Electron., vol. 4, no. 1, pp. 116-125, Mar. 2016.

[19] G. Stamatiou and M. Bongiorno, "Stability analysis of two-terminal VSC-HVDC systems using the net-damping criterion," IEEE Trans. Power Deliv., vol. 31, no. 4, pp. 1748-1756, Aug. 2016.

[20] L. Harnefors, M. Bongiorno, and S. Lundberg, "Input-admittance calculation and shaping for controlled voltage-source converters," IEEE Trans. Ind. Electron., vol. 54, no. 6, pp. 3323-3334, Dec. 2007.

[21] X. Wang, L. Harnefors, and F. Blaabjerg, "Unified impedance model of grid-connected voltage-source converters," IEEE Trans. Power Electron., vol. 33, no. 2, pp. 1775-1787, Feb. 2018.

[22] J. Lyu, X. Cai, and M. Molinas, "Frequency domain stability analysis of MMC-based HVdc for wind farm integration," IEEE J. Emerg. Sel. Top. Power Electron., vol. 4, no. 1, pp. 141-151, Mar. 2016.

[23] — , "Optimal design of controller parameters for improving the stability of MMC-HVDC for wind farm integration," IEEE J. Emerg. Sel. Top. Power Electron., pp. 1-1, 2017.

[24] J. Lyu, Q. Chen, and X. Cai, "Impedance modeling of modular multilevel converters by harmonic linearization," in 2016 IEEE 17th Work. Control Model. Power Electron. IEEE, Jun. 2016.

[25] M. Beza, M. Bongiorno, and G. Stamatiou, "Analytical derivation of the ac-side input admittance of a modular multilevel converter with openand closed-loop control strategies," IEEE Trans. Power Deliv., vol. 33, no. 1, pp. 1-1, Feb. 2017.

[26] J. Khazaei, M. B. Beza, and M. Bongiorno, "Impedance analysis of modular multi-level converters connected to weak ac grids," IEEE Trans. Power Syst., pp. 1-1, 2017

[27] J. Sun and H. Liu, "Sequence impedance modeling of modular multilevel converters," IEEE J. Emerg. Sel. Top. Power Electron., vol. 5, no. 4, pp. 1427-1443, Dec. 2017.

[28] L. Bessegato, S. Norrga, K. Ilves, and L. Harnefors, "Ac-side admittance calculation for modular multilevel converters," in 2017 IEEE 3rd Int. Futur. Energy Electron. Conf. ECCE Asia, IFEEC - ECCE Asia 2017. IEEE, Jun. 2017, pp. 308-312.

[29] K. Sharifabadi, L. Harnefors, H.-P. Nee, S. Norrga, and R. Teodorescu, Design, control and application of modular multilevel converters for HVDC transmission systems. Chichester, UK: John Wiley \& Sons, Ltd, 2016.

[30] J. Sun, "Small-signal methods for ac distributed power systems-A review," IEEE Trans. Power Electron., vol. 24, no. 11, pp. 2545-2554, Nov. 2009.

[31] J. Sun and K. J. Karimi, "Small-signal input impedance modeling of line-frequency rectifiers," IEEE Trans. Aerosp. Electron. Syst., vol. 44, no. 4, Nov. 2008.

[32] K. Ilves, L. Harnefors, S. Norrga, and H. P. Nee, "Analysis and operation of modular multilevel converters with phase-shifted carrier PWM," IEEE Trans. Power Electron., vol. 30, no. 1, pp. 268-283, Jan. 2015. 